\title{
VOZES AMERÍNDIAS DAS AMÉRICAS: LITERATURA, DESCOLONIZAÇÃO E AUTODETERMINAÇÃO
}

Roland Walter ${ }^{*}$

${ }^{1}$ Universidade Federal de Pernambuco, Recife, PE, Brasil

\begin{abstract}
Resumo
Este trabalho analisa como escritores ameríndios desenham um mapa de uma geografia crítica ao delinear a inter-relacionada brutalização dos seres humanos e do (meio) ambiente na interface colonização/descolonização. Baseado em uma abordagem teórica comparativa e interdisciplinar, embutida nos Estudos Culturais/Pós-Coloniais e na Ecocrítica, o ensaio problematiza a questão da identidade ameríndia atrelada a terra e à prática da cultura e língua dentro de contextos de (neo)colonialidade e revela a relação quebrada entre sujeito, língua, lugar e mundo que constitui uma das fontes principais do entre-lugar em textos de autores ameríndios do Brasil, do Peru e dos Estados Unidos.

Palavras-chave: Literatura Ameríndia; Identidade; Cultura; Oralidade; Colonialidade
\end{abstract}

\section{AMERINDIAN VOICES OF THE AMERICAS: OF LITERATURE, DECOLONIZATION AND SELF-DETERMINATION}

\begin{abstract}
The objective of this work is to analyze how indigenous writers of the Americas draw a map of a critical geography by delineating the interrelated brutalization of human beings and the environment at the colonial/decolonial interface. Its theoretical approach is comparative and interdisciplinary and embedded in Cultural/Post-Colonial Studies and Ecocriticism with the objective to problematize the issue of identity attached to the land and the practice of culture and language within contexts of (neo)coloniality, revealing the broken equation between subject, language, place and the world that constitutes one of the principal
\end{abstract}

\footnotetext{
"Professor Titular do Departamento de Letras da Universidade Federal de Pernambuco e Pesquisador do CNPq. Doutor em Literatura Comparada pela Johannes Gutenberg Universität e fez pós-doutorado na University of California. É autor de três livros - Magical Realism in Contemporary Chicano Fiction (Vervuert, 1993), Narrative Identities: (Inter)Cultural In-Betweenness in the Americas (Peter Lang, 2003) e Afro-América: Diálogos Literários na Diáspora Negra das Américas (Bagaço, 2009) -, editou o e-book As Américas: Encruzilhadas Glocais (Ed.UFPE, 2007), coeditou os livros Narrações da Violência Biótica (Ed.UFPE, 2010) e Entre Centros e Margens: Literaturas Afrodescendentes da Diáspora (Ed. CRV, 2015). Publicou numerosos artigos e capítulos de livros no Brasil e no exterior. Foi Editor-Associado do periódico acadêmico MELUS (Multi-Ethnic Literature of the United Sates) e Professor Visitante na Eberhard-Karls Universität. Seu e-mail é: walter_roland@hotmail. com. ORCID: https://orcid.org/0000-0001-9026-6870.
} 
sources of in-betweenness in texts by indigenous writers form Brazil, Peru and the United States.

Keywords: Amerindian Literature; Identity; Culture; Orality; Coloniality 
"I know this. Land is the only thing that lasts life to life" (Louise Erdrich). "Homens, árvores, serras, rios e mares são um corpo, com ações interdependentes" (Kaka Werá Jecupé). "when you move through those old steps, remember that you are dancing a rebellion" (Susan Power).

Genocídios, escravizações, sistemas de plantação, subalternizações, resistências, guerras: eis a conturbada história das Américas resumida em seis termos. Seis termos acompanhados por uma "memória quebrada", segundo Eduardo Galeano $\left(2005\right.$, p. 93) ${ }^{1}$ ou, como ele também a chamou, "a memória sequestrada das Américas" (1982, p. 12), ${ }^{2}$ dentro de uma "não historia" (GLISSANT, 1992, p. 62): uma história esquizofrenicamente caracterizada por lacunas e rupturas com base na violação dos direitos humanos, vegetais e animais. Francisco Alarcón (1992, p. 34) argumenta que as Américas continuam a ser "invadidas, ocupadas, branqueadas, fragmentadas, higienizadas, suprimidas e/ou ignoradas"3. Com o efeito devastador que Antônio Cornejo-Polar (2000, p. 147) destacou nos seus ensaios, falando da "heterogeneidade" e da "índole quebrada" das nações latino-americanas. Se para Michel Foucault (1986, p. 24) o espelho é o meio para explicar a heterotopia em termos universais, Joaquín Brunner (1988, p. 15) descreve a realidade fractal da América Latina como um "espelho trincado" e Robert Schwarz (1992), as ideias do Brasil como "fora do lugar": uma realidade quebrada, fissurada por graves conflitos étnico-culturais em que a razão da subalternização, marginalização, difamação e discriminação, e para utilizar o termo de Enrique Dussel (1995, p. 69), a "razão do Outro" ${ }^{5}$ embatem numa polarização acirrada nos espaços fronteiriços (neo/pós-)coloniais - espaços onde as pessoas estão incluídas em e excluídas por mercados locais e globais, lutas étnicas, raciais e de gênero e projetos regionais e nacionais caracterizados por descontinuidade; espaços onde as pessoas assimilam e resistem às ideias, forças e práticas num móvel e contínuo processo de identificação; espaços violentos onde esses processos de construção identitária dançam ao ritmo sincópico da "colonialidad del poder" (Quijano) enquanto efeito das diversas relações coloniais e imperiais/imperialistas.

A literatura ameríndia contemporânea nas Américas é um produto da relação colonial entre europeus e ameríndios. "Cada palavra escrita em inglês", observa Louis Owens (1998, p. 6) a respeito da literatura ameríndia dos Estados Unidos, "representa um tipo de colaboração e uma reorientação - consciente ou inconsciente - do mundo paradigmático da tradição oral para a realidade sintagmática da linguagem escrita". ${ }^{6}$ Este lugar entre epistemes culturais que implica a dessacralização de material sagrado que move do âmbito oral, coletivo, à arte secular escrita, individual é, de certa forma, um espelho heterotópico da entre-condição dos povos ameríndios nas Américas. A colocação dos ameríndios em reservas enquanto símbolo geográfico-ideológico da violência do regime (neo)colonial significa também uma desterritorialização identitária e epistêmica que continua enquanto colonialidade até hoje. A brutalização dos ameríndios é um genocídio que se iniciou com a chegada dos colonizadores europeus e ainda não terminou. 
Perante esse fundo, gostaria de destacar e analisar como escritores ameríndios das Américas problematizam a existência entre a dominação e a sedução da cultura hegemônica do não ameríndio e a resistência e a resiliência da cultura autóctone na interface colonização/descolonização. Trata-se de examinar em poesia e romances selecionados o desenho de um mapa de uma contínua descontinuidade compartilhada por gerações; uma geografia crítica em que vibra, entre os ditos e não ditos, a dupla e inter-relacionada brutalização dos seres humanos e do seu (meio) ambiente; brutalização esta que constitui de diversas maneiras o inconsciente sociocultural e ecológico da experiência pan-americana - o fantasma do genocídio ameríndio recalcado que volta em resposta à Verleugnung (negação) fazendo sentir sua presença tanto no nível da enunciação quanto no da experiência vivida e imaginada.

Se cultura for definida como experiências vividas e imaginadas do ser humano com seu meio ambiente e práticas significantes compartilhadas que constroem relações sociais no lugar que habita, poder-se-ia argumentar que o cerne do problema identitário que diz respeito às nações ameríndias é a relação com a origem num espaço roubado, vendido, imposto. Ter uma identidade significa ter uma história inscrita na terra. Ter uma história enraizada na terra roubada durante o processo colonial, como no caso dos povos ameríndios, significa ter uma não identidade. Refletida e refratada nesta não identidade - uma identidade fragmentada e/ou alienada por condições de violência - é a importância da geografia e da memória para se situar como sujeito. Sem lugar, a consciência e a subjetividade do ser humano são inconcebíveis. Este lugar pode ser de natureza geográfica e/ou linguística, religiosa, cultural, um lugar epistêmico. Para povos colonizados e grupos marginalizados, o processo da descolonização e desmarginalização significa a transformação do lugar unheimlich - o lugar (e a correspondente episteme cultural) da subalternização - num lugar heimlich; um lugar-lar onde a relação entre o mundo, a imagem do self e a língua/linguagem são reestruturados com base no próprio ethos e cosmovisão. No que toca os povos ameríndios, essa relação quebrada constitui uma das fontes principais do entre-lugar identitário - da transculturação identitária. Um entre-lugar enquanto trans/relocação onde os gritos e falas subalternizadas ecoam nos silêncios forçados de uma contínua transculturação cuja violência é epistêmica, física e ecológica. O lugar-lar e sua construção na língua, portanto, é um dos meios cruciais para lembrar (e assim juntar) os fragmentos de uma cultura/história/ identidade estilhaçada e parcialmente perdida nos traços nômades entre lugares e representações bem como entre os muitos ditos e não ditos na interface ambígua e escorregadia da língua colonizadora e autóctone.

Outro meio de descolonização, talvez o mais importante no caso das nações ameríndias, é a luta jurídica pela posse/reconquista/demarcação e não invasão da terra, já que a questão da terra é crucial para a definição da episteme sociocultural e produção da subjetividade e identidade individual e coletiva, ou seja, a maneira como o indivíduo vê a sua posição de sujeito numa dada sociedade (ethos) e como, a partir dessa posição, vê o mundo (cosmovisão). Em cada cultura, a terra 
tem um papel fundamental na constituição do imaginário cultural de um povo: ela é tanto natural quanto cultural; uma entidade material e uma ideia/visão mítica que participa na definição identitária e, em contextos (neo)coloniais, é crucial para a reconstituição identitária num processo de descolonização.

Escritores, pensadores e ativistas ameríndios enfatizam a importância da terra enquanto base de sustentação tanto física quanto espiritual. Nesse sentido a escritora lakota Leslie Marmon Silko (1997, p. 36-37) diz que "a paisagem ressoa a dimensão espiritual-mítica do mundo pueblo mesmo hoje"; "características geográficas e lugares conhecidos que são mencionados nas narrativas existem para propósitos rituais"'; ou seja, têm importância para recriar o caminho do passado ao presente, entender-se enquanto coletividade via processo de imaginação mnemônica. Com relação à oralização da memória, Silko observa que ouvindo as histórias, ela é capaz de "visualizar-se como sendo situada dentro da história contada, dentro da paisagem". Portanto, “a identidade foi ligada com o território, a paisagem, que muitas vezes teve um papel significante na história ou no desfecho de um conflito" (1997, p.43) ${ }^{8}$. Nessa forma de ser/pensar, a compreensão da terra emerge como construto dominante que situa o tempo, a espiritualidade (o sagrado, o mito), a ideologia e a comunidade, ou seja, a identidade individual e coletiva vivida, imaginada e lembrada, em relação com a terra. Implícito nesta cosmogonia é que o poder não consiste em ser proprietário de terra, mas é mediado em visões, sonhos, a capacidade de entrar em contato com os espíritos que vivem na natureza, habitando as diversas esferas da terra e nas ações que resultam dessas mediações. Nas palavras de Ward Churchill (1992, p. 131):

A terra [...] é a questão absolutamente essencial ao definir concepções viáveis da América Nativa [...]. Um profundo senso de unidade com contextos geográficos particulares tem fornecido o cimento espiritual que permite coesão cultural através de todo o espectro das sociedades ameríndias?.

Lugares sagrados, o que Vine Deloria Jr. (1994, p. 122) chama de "geografia sagrada"10, significa mais que comunidade lembrada; são lugares de presença dos ancestrais e seres espirituais que viabilizam mandato e significação e, nesse sentido, são, nas palavras de Lawrence Grossberg (1992, p. 82) "os lugares nos quais as pessoas podem se ancorar no mundo, a localização das coisas que têm importância"11. Em The Names N. Scott Momaday (1976, p. 142) escreve: "Os eventos da vida de uma pessoa acontecem num lugar, acontecem num lugar... Existi nesta paisagem e depois a minha existência era indivisível dela"12. Da mesma maneira, Mary Crow Dog (com Richard Erdoes, 1990, p. 220) escreve que "a terra é a nossa mãe, os rios, o nosso sangue"13.

A United Nations Declaration on the Rights of Indigenous Peoples, em resolução adotada em 2007, enfatiza nos artigos 3 e 4 o direito dos povos ameríndios de autodeterminação ("self-determination") e "governo autônomo" ("self-government"), e que os Estados-nação em colaboração com os povos ameríndios, deveriam garantir a proteção de mulheres e crianças ameríndias contra todas 
as formas e práticas de violência. Em The Round House, a escritora ameríndia norte-americana Louise Erdrich problematiza a falta de soberania dos povos ameríndios nos Estados Unidos e no Canadá. O romance denuncia que ao tirar "de nós o direito de processar pessoas não ameríndias que cometem crimes nas nossas terras" - neste caso específico o estupro brutal de uma mulher ameríndia por um homem branco - "a despossessão das nossas terras" continua (2012, p. $229)^{14}$. Muitas nações ameríndias são sujeitadas à jurisdição federal, ou seja, elas não têm autonomia judicial ou somente têm de maneira parcial e limitada. Para muitos povos ameríndios um sistema judicial independente, ou seja, ameríndio, é uma preocupação tão importante quanto o direito às terras ancestrais; direito este garantido pela Inter-American Court e pela OAS Inter-American Commission on Human Rights, mas, segundo o Amnesty International Report 2017/18 (p. 32), não ou insuficientemente promulgado pelos estados-nação interamericanos. Com base nesse Report, os direitos humanos das nações ameríndias através das Américas continuam sendo violados e as terras ameríndias continuam sendo alvo de interesses capitalistas, entre eles principalmente os do turismo, da mineração, da indústria agrícola e da indústria madeireira.

No livro, ¿Por Qué No Cuidar a Esos Montes Sagrados? Girvan Tuanama Fasabi trabalha o tema da terra enquanto episteme cultural. O livro, - um grito em defesa da Pachamama, do direito da comunidade Kawana Ampi Urku las Palmeras no departamento de San Martín, na Amazônia peruana, de decidir sobre o destino das terras que habitam desde gerações, - defende o uso e o cultivo coletivo da terra pela comunidade ameríndia contra a intrusão das redes multi/transnacionais que se apropriam dessas terras com o objetivo de explorar os recursos naturais; um processo de neocolonização tolerado se não ativamente incentivado pelas diferentes instâncias governamentais que leva à diasporização étnica e ao desenraizamento cultural. As autoridades regionais e nacionais, segundo o autor, não "escutam as vozes das comunidades locais, a posição das comunidades [...] queremos o território para garantir que os filhos dos nossos filhos tenham água, conheçam sequer um peixe”. (2012, p. 18) ${ }^{15}$. O que está em questão aqui - como em muitas partes das Américas e do mundo inteiro - não é somente a subsistência das existências humanas, vegetais e animais, mas uma episteme cultural com base no círculo que une os seres bióticos em harmonia e igualdade: uma cosmogonia/cosmologia articulada numa língua específica, o quéchua neste caso, que forma a base do ser-estar étnico-cultural. Resume Fasabi (2012, p. 27): "E me pergunto, pois, quando desmatamos todo este monte, aonde vão os espíritos? Por que não cuidar destes montes sagrados?"16. Na palavra 'cuidar' que Fasabi utiliza - um termo oposto a 'tirar,' 'explorar', 'possuir,' 'lucrar', 'consumir' - vibra a questão do saber, da "Cuidadania"17 enquanto cidadania engajada: o dever dos seres humanos de saber de si mesmo e dos outros em nome de uma convivência interbiótica baseada em harmonia, justiça e paz - sumak kawsay em quéchua ${ }^{18}$.

Semelhante à Erdrich e Fasabi, a poesia de Graça Graúna problematiza a relação fissurada entre a terra e seus habitantes ao articular raiva e tristeza sobre a desterritorialização contínua que os povos afrodescendentes e ameríndios 
sofrem no Brasil e nas Américas: uma transculturação forçada que não resulta em fusão cultural, mas fissuras, confrontos culturais constituídos por elementos bióticos sem raízes; elementos incapazes de se ler um ao outro, aprender e compreender-se através do/a outro/a. Ao declarar em "Manifesto" que ela, enquanto afro-potiguara, não conhece mais "o que ainda resta / do cheiro da mata / da água / do fogo / da terra e do ar", que ela perdeu a sabedoria de ler "a terra / sangrando por dentro", Graúna fortemente denuncia a contínua desapropriação e destruição das terras ameríndias, como também a nossa alienação biótica na era digital caracterizada por um saber tecnológico que nos priva de uma experiência interbiótica vivida. Na sua poesia, as sombras da colonialidade se refletem no que ela chama em "Manifesto" a "plastifica[ção] [d]o verde" pelos invasores cuja ganância "paviment[ou] o destino" dos primeiros habitantes destas terras. No poema "O Guarani” em homenagem a Sepé Tiaraju, Graúna aponta para um dos problemas da nação brasileira, a saber: a questão da terra roubada e não devolvida: "Da real história poucos sabem / o que se deu no século dezoito / Sepé Tiaraju morto em combate / em nome da cultura do seu povo. / Junto a mil e quinhentos guaranis / afirmando que 'esta terra já tem dono'. / Na luta contra o mal ele morreu" (1999, p. 51). Em "Canción peregrina" a voz poética enfatiza o entre-lugar dos ameríndios nos países latino-americanos: "Yo canto el dolor / desde el exílio" (2009, p. 27). A voz poética se delineia como "fragmento [...] da fúria no choque cultural" (Manifesto) "gritando la angustia acumulada" (2009, p. 28). O grito enquanto atitude decolonial articula "o valor e a importância da raiva" ("Poética da autonomia") na reconstituição da subjetividade dilacerada. Destarte, o grito trabalha o trauma do passado para transformá-lo em memória coletiva consciente, capaz de construir um caminho que leve a uma existência em que o autodesprezo é substituído por autoestima. A cura deste trabalho de resistência às formas e práticas (neo)coloniais reside na estetização da violência sofrida, ou: "dançamos a dor / tecemos o encanto / de índios e negros / da nossa gente” (2006, p. 120). Em outras palavras, para poder tecer a identidade ameríndia no presente, é necessário atravessar os eventos/tempos dolorosos, trazê-los à superfície da consciência mediante uma perlaboração que possibilite a transformação da dor traumática em energia criativa. Ao re-imaginar o passado, reapropriando-o do discurso hegemônico com suas lacunas de falsificação e distorção ideológicas, Graúna imbui o entre-lugar como não lar ameríndio/afrodescendente de um desejo de lar sem vestígios (neo) coloniais cujo fundamento seja a autodeterminação baseada em soberania sociocultural e política-económica.

Dois aspectos-chave ligam os textos de Erdrich, Fasabi e Graúna: a questão da terra e sua relação com a episteme cultural e a soberania de escolher os valores culturais e disposições individuais que nos fazem agir de certas formas e não de outras num certo lugar com base em certas normas e leis. Nesse sentido, as mitopoéticas de Erdrich, Fasabi e Graúna, em sua diferença, denunciam uma das características mais importantes das terras americanas que William Faulkner em Go Down, Moses, referindo-se aos Estados Unidos, descreve como "a maldição desta terra", "aquele complexo edifício todo fundado em injustiça e erigido por 
rapacidade cruel" (1977, p. 291) transformando "a terra virgem" em "terra subjugada" (1977, p. 252) ${ }^{19}$.

A articulação mitopoética é um meio de revelar, denunciar e transformar a contínua colonialidad del poder (Quijano) através de uma revisão da história no sentido de Adrienne Rich (1979) e, neste processo, recolocar a identidade dentro de uma episteme cultural recordada e rearranjada, ou seja, a língua, as categorias e processos de fundação que dão sentido às coisas e acontecimentos; valores mediante os quais nos recordamos, sabemos, interpretamos as coisas e agimos conforme. No romance Slash $(1988$, p. 211) da escritora canadense Jeannette Armstrong do povo okanagan, a voz narrativa explica esse processo de conscientização mediante a relação crucial entre cultura, língua, lugar e identidade da seguinte forma:

A nossa cultura é assim. Você a protege usando-a. É a mesma coisa com este lugar. $\mathrm{O}$ que a gente quer realmente preservar são as nossas maneiras. [...] São elas que é preciso preservar; assim este lugar pode ser protegido porque tem um propósito de ser protegido. Você tem que aprender essas coisas e transmiti-las aos outros. [...] A mesma coisa com a língua. [...] Somente usando-a podíamos preservá-la ${ }^{20}$.

A preservação dos costumes e hábitos de um povo significa que estes têm que ser praticados, usados, vividos, sentidos, imaginados, articulados: a vivência cultural num lugar dentro de um processo histórico. Em outras palavras: sem lugar e língua não há memória, nem identidade. A terra é uma casa onde os ancestrais, os espíritos, as divindades, os que vivem e os que viverão (humanos e não humanos) constituem o círculo de múltiplas memórias, vivências e histórias. Em seguida, examinarei a memória e identidade fragmentada, estilhaçada no romance Power de Linda Hogan dos Estados Unidos com o objetivo de problematizar o entre-lugar cultural e identitário na escrita ameríndia.

Em Power de Linda Hogan, Omishto, uma adolescente de dezesseis anos, vive entre duas culturas e estilos de vida: o mundo anglo e o mundo do seu povo, os taiga da Florida. Os limites desse entre-lugar cultural são constituídos pela escola, onde ela estuda "a guerra e os números que combinam para destruir a vida" (1998b, p. 105) ${ }^{21}$, sua mãe e irmã alienadas da cultura taiga, seu padrasto abusivo e sua tia Ama que a inicia nas tradições dos taiga via narração oral. A reconstrução identitária de Omishto é um processo de transição de um posicionamento "no meio entre o mundo moderno e o antigo" (p. 23) para uma vida "num mundo mais antigo", nas "selvas" (p. 218) 22 . Essa viagem pelo limen retrata a busca angustiante por parte dos ameríndios norte-americanos de um lugar-lar na fronteira que separa o mundo branco, que os trata como subalternos, do mundo dos taiga que existe como vestígio tênue. Situada entre esses dois mundos como se fosse duas pessoas, Omishto, igual a tantos outros personagens na ficção ameríndia dos Estados Unidos ${ }^{23}$, não se sente à vontade nem na sua cultura ameríndia, cujo idioma ela não fala, nem na cultura branca em que será sempre "uma pessoa dissolvida, como o sal na água" (p. 231) 24 $^{4}$ existindo na sombra do inconsciente 
roído de culpa e traduzida em raiva e violência do colonizador. Omishto, depois de tentar ligar os dois mundos ao se distinguir na escola e passar tempo com Ama e sozinha na natureza, opta por uma vida tradicional no seio da nação taiga.

A seguinte discussão analisa como Hogan traduz a travessia de Omishto através do limen enquanto espaço fronteiriço, postulando que Hogan consegue curar a subjetividade dilacerada de Omishto por meio de uma narração oral, uma cerimônia ritualística baseada no poder da palavra, que, igual ao fôlego, significa a vida. Power articula o que Hogan enfatizou em Dwellings, ou seja, que "a história é o ponto crucial de cura" (1995, p. 37) e que "os mitos [...] são as mais profundas e íntimas histórias culturais das nossas viagens humanas em direção ao crescimento espiritual e psicológico" (p. 51) ${ }^{25}$ precisamente porque eles têm o poder de criar uma ligação significativa entre a experiência e o mundo vividos e imaginados.

É na fronteira intercultural - a interface onde a racionalidade branca com sua diferenciação das coisas e espécies em categorias separadas e a cosmogonia taiga com a conexão interbiótica do material e espiritual se encontram e interagem que Hogan delineia o árduo processo da formação identitária de Omishto por meio de uma afirmação da diferença cultural enraizada na memória e na tradição oral da nação taiga. As histórias mitopoéticas de Ama familiarizam Omishto com as origens dos Taiga e um tempo "quando as pessoas eram capazes de virar animais e os animais de se transformar numa forma humana" (1998b, p. 23) 26 ou seja, quando os seres humanos e não humanos viveram juntos em harmonia. Essas histórias do passado permitem Omishto compreender o presente pelo fato que "uma linha contínua de luz" conecta o passado com o presente e o futuro (p. 181), que "há forças invisíveis em volta de nós" (p. 14) com o poder de criar e destruir ${ }^{27}$.

Omishto aprende das histórias contadas por Ama, bem como da "sua tranquilidade", que ela chama de "silêncio cheio", não um silêncio imposto, mas um silêncio recriado que "te diz como conhecer as coisas" (p. 19) ${ }^{28}$, como conhecer as coisas atrás das coisas e compreender desde a interioridade à essência do lado interno e externo das coisas. Ambas as formas de comunicação - a narração oral e o silêncio -, portanto, constroem a consciência histórica e cultural de maneira coletiva ao envolver a narração da contadora e a imaginação da ouvinte, a liberdade de pensar sobre o dito e conectá-lo com o não dito num processo intersubjetivo que dissolve os limites entre o mundo material e espiritual.

Essa interioridade do saber ameríndio é percebida através de visões epifânicas. Segundo Paula Gunn Allen (1992, p. 116), a visão e o mito são interconectados no pensamento ameríndio: "O mito é a história de uma visão" e "a visão é uma maneira de se tornar inteiro, de afirmar o seu lugar especial no universo" 29. O poder transformativo de uma visão reside na interconexão harmoniosa de todas as coisas, percebida num continuum espaço-tempo no qual o "consciente e o inconsciente são unidos por meio da magia da progressão simbólica de modo que os símbolos podem transmitir significados racionais diretos e evocar memórias indiretas que não têm sido levantadas à articulação consciente" (ALLEN, 1992, p. 117 $)^{30}$. Quando Omishto, num episódio-chave do romance, vê quatro mulheres "em vestidos antigos [...] caminhando ligeiramente em cima do chão como se 
fossem deslizando sem pés [...] dançando [...] flutuando e cantando" (HOGAN, 1998b, p. 24-25) $)^{31}$, ela começa a ver e sentir o invisível e inexprimível - o sagrado que imbui tudo que existe. Ama, que não levanta os olhos e por isso não as pode ver, confirma a visão de Omishto: “"Veja-as caminhando [...]. Olhe para elas. [...] Deve ter boas notícias hoje. As mensageiras estão chegando"' (p. 25) ${ }^{32}$. Embora as quatro mulheres ${ }^{33}$ desapareçam de repente, Omishto acredita na veracidade de sua visão, sentindo que algo sagrado, algo misteriosamente poderoso acabou de acontecer: "[...] e olhando é como se visse o espaço entre as coisas, como se houvesse um lugar entre cada coisa sólida onde há criação" (p. 25-26) ${ }^{34}$. Nessa cena, tanto o énoncé (aquilo que é dito) quanto a énonciation (o processo de dizê-lo) produzem uma ligação harmoniosa entre diferentes ordens da realidade. Visto que as duas personagens não mostram nem hesitação nem surpresa perante a aparência das quatro mulheres, a narração faz com que o leitor acredite na sua realidade. A fusão da matéria com o espírito subjacente a esta visualização da realidade indica a conscientização e inerente mudança da posição cultural de Omishto. A visão inicia Omishto na cerimônia do seu regresso cultural - um ritual que relembra e apresenta o mito da criação taiga no presente, via uma reencenação do ciclo de vida e morte ${ }^{35}$. De acordo com o mito taiga, a pantera é uma pessoa sagrada ${ }^{36}$ porque primeiro, ela ajudou na criação da nação ao dizer a palavra "Oni", que significa "canção [...] oração [...] vento", e "vida" (p. 182) $)^{37}$, e segundo, depois de deixar um mundo em desequilíbrio por uma abertura soprada pelo vento, ela convida Pantera-Mulher, uma mulher criada por animais, a sacrificá-la para restaurar o equilíbrio do mundo. Este mito de criação narrado em fragmentos por toda a trama, explica a série simbólica de eventos que segue à visão de Omishto: uma tempestade que semeia destruição no mundo contemporâneo já desequilibrado e induz Ama a caçar e a matar uma das últimas panteras sobreviventes. Ao seguir a pista do animal tanto Ama quanto Omishto estão "carregadas em algo maior" (p. 62), algo que "tem acontecido antes e poderia acontecer de novo" (p. 44) ${ }^{38}$. Ama, uma mulher que sente uma profunda simpatia para com a pantera e a chama de 'Avó' durante a caça, Omishto compreende em retrospectiva, reencena o feito de Pantera-Mulher para "restabelecer a vida neste lugar que outrora estava bonito" (p. 111) ${ }^{39}$ e a conexão interrompida entre os seres humanos, os animais e os deuses. Embora Ama seja absolvida pela lei branca de ter matado um animal de uma espécie em vias de extinção, a lei taiga a bane da nação por ter agido individualmente, sem consultar os outros, e por ter deixado de entregar o animal morto ao conselho dos anciãos. Ama, porém, quer poupar seu povo da contemplação de um animal enfermo, faminto, meio-morto - contemplação esta que, segundo Ama, teria acabado com as esperanças dos taiga de reconectarem-se com os hábitos e crenças tradicionais. Ama, como a Pantera-Mulher de outrora, desaparece, sacrificando a pantera e a si mesmo para que aconteça essa reconexão; processo este que se materializa quando Omishto, a esperança dos taiga na sobrevivência, no futuro, vê uma pantera sã, magra, mas com músculos e desperta certa manhã com seu corpo coberto de arranhões de pantera (p. 233), unindo-se às quatro mulheres, caminhando para o lugar da nação, dizendo: 
Neste momento, sou mais do que só eu. Sou eles. Sou o antigo. Sou a terra. Sou Ama e a pantera. [...] Todos os espíritos do mundo congregam no ar [...]. Respiro-os e sinto-os. No meu fôlego encontra-se o cantar dos antecedentes que vivem no limite do céu. Igual as ondas distantes eles chegam à margem dos vivos $\left(\right.$ p. 173, 179) ${ }^{40}$.

A força transformativa dessa performance ritualística consiste no poder inerente às palavras: o potencial criativo e destrutivo das palavras enquanto visões mentais do físico. A linguagem, a estética da narração oral, serve de meio para estabelecer, manter e/ou restaurar a ligação entre a experiência do ser humano como parte de um coletivo num lugar específico, os deuses, os espíritos e outras espécies bióticas/cósmicas dentro de um processo histórico fluido. ${ }^{41} \mathrm{~A}$ literatura ameríndia norte-americana, afirma Paula Gunn Allen (1992, p. 61), é baseada na "cerimônia e no mito. A cerimônia é a encenação ritualística de uma percepção especializada de uma relação cósmica, enquanto o mito é a história em prosa desta relação" ${ }^{42}$. Se bem que aspectos e símbolos desta encenação variam entre as diversas nações, o propósito da cerimônia é o de curar divisões e cisões e de criar harmonia e inteireza entre as coisas, uma relação dinâmica entre o indivíduo, o coletivo e o universo. Portanto, argumenta Allen (1992, p. 80), a literatura ameríndia, "que inclui a cerimônia, o mito, o conto e a canção, é o modo principal da tradição ritualística" ${ }^{43}$, tradição esta que sempre tem sido baseada na palavra falada. Contar histórias, uma memória-cerimônia oral, é, segundo Allen (1992, p. 53), a fonte mais importante para os escritores ameríndios contemporâneas, uma fonte "à qual se remetem continuamente referente ao tema, ao símbolo, à estrutura e ao impulso motivador bem como à orientação filosófica que anima nosso trabalho" ${ }^{4}$. Enquanto elemento constitutivo de uma cosmovisão enraizada na interconexão de diferentes esferas e suas ordens de coisas, a tradição oral deveria ser considerada como uma importante força da resistência ameríndia à colonização contínua e como um meio para relocalizar sujeitos descentrados no seio da comunidade. Segundo Allen (1983, p. 3 , 4), a narração oral-escrita, a oralitura, enquanto "literatura cerimonial" é uma forma de "medicina" que influencia a consciência, o ethos e a cosmovisão de um povo na medida em que ela "serve para redirigir a emoção pessoal e integrar a energia gerada pela emoção dentro de uma moldura cósmica" ${ }^{\text {" }}$. Ao inscrever a existência de um grupo étnico num sistema específico de verdade, a linguagem recria e deste modo representa o mundo e a realidade e, ultimamente, como afirma Simon Ortiz em entrevista concedida a Coltelli (1990, p. 108) "é a vida" ${ }^{4}$. Nas palavras de Hogan (1995, p. 80-81), "em quase todos os relatos de criação [...] a vida foi articulada para sua existência via linguagem, pensamento, sonho, canção, atos de consciência interior" ${ }^{\prime \prime 7}$.

A narrativa mitopoética de Hogan é baseada em palavras que evocam no leitor visualizações da ligação entre o material e o espiritual, ou seja, palavras que estabelecem a ideação da experiência humana mediante uma relação dinâmica com o mundo ao redor. Por causa dessa rede dinâmica de diferentes esferas e espécies, uma variedade de pontos de vista e percepções é negociada no processo 
aberto de construir a realidade. Omishto explica a relação entre as palavras e a realidade da seguinte forma:

as palavras [...] são uma pessoa; elas se originam das dores do parto do sonho e do pensamento. Articuladas, as palavras colocam-se [...] em pé como deuses delgados e, [...] então, algo recém-nascido e vivo permanecerá no ar, na água e neste mundo. Este algo ficará aqui em tempos de necessidade. [...] É algo que sustentará (HOGAN, 1998b, p. 181) ${ }^{48}$.

Em outras palavras, o ato de falar imbuído de valores tradicionais constitui um processo de cura caracterizado pela ligação entre todos os elementos e coisas num fluxo de poder criativo compartilhado por todas as espécies bióticas. A narração desse processo de cura não é mera descrição, mas também uma performance de como a vida foi e continua sendo criada via palavras, suas imagens e as visualizações dos envolvidos.

Neste sentido, Hogan é uma contadora de histórias que fala-escreve o texto primário do mito taiga através das experiências de Omishto e Ama. A tempestade, a caça da pantera e a problematização do feito de Ama no fogo cruzado entre a jurisprudência angla e taiga têm um duplo significado interconectado. No nível racional revelam o embate de duas culturas e a divisão intraétnica entre os ameríndios que optam pelo way of life e valores da sociedade dominante e os que permanecem fiéis aos pensamentos e valores tradicionais dos taiga. No nível mitopoético, reencenam o passado como mito primário no presente. Os dois níveis são conectados pela busca identitária de Omishto. Ao situar Omishto no processo criativo do mito, a narração permite-a tomar seu lugar dentro da nação taiga. Ao demonstrar que a travessia do espaço fronteiriço envolve a responsabilidade individual e coletiva - um contrato mútuo entre seres humanos e não humanos - Hogan assume o papel tradicional de orador enquanto curador. O poder da medicina hoganiana consiste na articulação de uma cosmovisão caracterizada por limites fluidos entre os diversos elementos bióticos, ou, nas palavras de Hogan (1998, p. xiv.): "Somos todos o mesmo mundo dentro de diferentes peles e com diferentes inteligências". Ao descobrir essa "linguagem interior" (HOGAN, 1995, p. 57 $)^{49}$ que a une com a natureza e seu povo, os taiga, Omishto desconstrói a fronteira entre a natureza e a cultura. Power, portanto, é a representação cerimonial de uma visão da realidade em busca de harmonia e criação oposta às definições socioculturais/bióticas do eu e do universo que, baseadas em divisões, levam à destruição da vida neste planeta.

Por outro lado, a integração ritualística de Omishto no Clã das Panteras taiga demonstra a necessidade de limites étnico-culturais no processo da reconstrução identitária. Se, segundo Krasteva (1999, p. 50), “a política da fronteira sempre gira em volta das tensões entre a identidade imposta e a autodefinição" ${ }^{30}$, então Hogan, por meio da viagem de Omishto, revela quem erige fronteiras e com que objetivo. No romance, a situação adversa dos taiga e da pantera é um resultado da colonização interna, aquilo que Omishto chama o "mundo traído" ${ }_{11}$ (HOGAN, 1998b, p. 72) - a invasão cultural da sociedade branca que sistematicamente 
empurrou para diante sua devastadora fronteira de separação tanto contra povos ameríndios quanto contra a natureza. O poder invasor da cultura branca é traduzido pela imagem do tribunal onde o processo de Ama tem lugar:

Este prédio é um mundo cortado em dois. Este prédio e o que ele contém dividem uma parte da vida da outra. Ele tem separado por cicatrizes, roubo legal, até a pedra da terra partida e carregada aqui a um prédio de justiça, e depois cobre tudo o que foi quebrado com palavras, assim como a planta $k u d z u$ do velho mundo cobre este chão bonito de sufocantes trepadeiras estrangeiras (HOGAN, 1998b, p. 118)

Duas filosofias, duas culturas, duas cosmovisões entrechocam-se aqui, constituindo uma zona de contato onde diferentes histórias, experiências e vozes se encontram numa relação de poder antagônica: a lei escrita de subjugação que define uma relação hierárquica com o Outro e a lei oral, "mais forte e velha do que a América" (p. 160) ${ }^{53}$, baseada na interpretação espiritual-material do ser humano e seu meio. Visto que a política do colonialismo interno apoia-se em palavras mentirosas (p. 120) - palavras que constituem a episteme que impõe o significado ao Outro e estabelece o saber a si mesmo, palavras que distorcem ou apagam episódios da história específicos, palavras que articulam políticas de aculturação - as leituras falsas do feito de Ama por parte dos ambientalistas e do sistema judicial branco frustram a compreensão intercultural. E mais, a política da eliminação e/ou assimilação ameríndia subjacente à construção da nação norte-americana tem prejudicado a compreensão entre os povos e dentro destes. Quando os membros da corte taiga banem Ama, eles erram, interpretando a morte da pantera sagrada como uma violação intencional da lei taiga. Embora esta leitura errada se deva atribuir principalmente ao silêncio de Ama no tocante ao motivo de sua atuação, ela também revela a fronteira da lei tradicional que separa os taiga dos outros. Esse "círculo criado por gerações" com suas "linhas fronteiriças grossas demais para serem desenhadas ou tornadas físicas neste mundo" (p. 173) ${ }^{54}$ é o esteio cultural da luta de sobrevivência dos taiga. É esse círculo, enquanto fronteira, que faz valer sua diferença cultural, a arma espiritual numa luta contínua contra a dominação, absorção, ou seja, o genocídio ${ }^{55}$. A descolonização ameríndia, Hogan nos faz lembrar em Power, envolve primeiro e, principalmente, recuperar a posse do eu fragmentado e alienado mediante a recriação de uma identidade estável. Significa sair do espaço fronteiriço entre culturas, que no caso de Omishto é uma zona transcultural de guerra destrutiva, e recorrer a um lugar dentro da fronteira étnico-cultural que circunscreve o ethos e a cosmovisão da nação taiga.

Penso que uma grande parte da literatura ameríndia contemporânea em sua diferença é unida pela perlaboração do genocídio sofrido. Contra o contínuo processo de (neo)colonização - uma violência física, epistêmica e ecológica cujo objetivo é a transformação/aniquilação da identidade e do ser-estar no mundo dos ameríndios - a resistência decolonial via memória mitopoética pode ser definida como o árduo processo de encontrar/revelar/entender os vestígios culturais do passado no presente para reimaginar/reescrever a história de uma 
perspectiva autóctone. A reconstrução do self dilacerado por formas e práticas violentas de (neo)colonização, a autodeterminação individual e coletiva precisa esse conhecimento histórico para materializar-se. Nesse sentido, o saber não se estabelece em abstrações mediante uma assimilação cultural forçada, mas é a capacidade de fazer referência às experiências do passado e contextualizá-las num sistema de significação que explica as experiências vividas e imaginadas do presente. Para muitos povos ameríndios, a libertação da desumanizante colonização contínua significa, portanto, reconectar-se com as histórias e rituais mitopoéticos dos ancestrais e espíritos - que não habitam o céu, mas a terra, ou nas palavras de Margaret Many Wounds no romance The Grass Dancer de Susan Power (1995, p. 296), "o limite do mundo" 56 - porque, segundo Betty Bastien (2005, p. 48) do povo blackfoot, "o saber e as verdades florescem por meio das nossas relações e conexões com o mundo natural" ${ }^{\prime \prime}$. Ela resume a descolonização da seguinte maneira: "a autodeterminação significa o poder de se definir e determinar seu destino" (p. 63) dentro da sua episteme autóctone..$^{58}$ Neste processo, argumento, as literaturas ameríndias das Américas problematizam os diversos assuntos que tocam a vida contemporânea dos autóctones mediante a recriação do imaginário ameríndio e contribuem para a retificação da representação dos ameríndios como seres desumanos, selvagens, primitivos e exóticos na história oficial. Assim, movem via "passos antigos" "dançando uma rebelião" (POWER, 1995, p. 299), como se pode ler na terceira epígrafe deste ensaio. Esta "resistência indígena", escreve Gail Guthrie Valaskakis em Indian Country "é persistência cultural" 59 .

Notas

1. No original: "mémoire brisée". As traduções apresentadas neste ensaio são de minha autoria.

2. No original: "la memoria secuestrada de toda América".

3. No original: "invaded, occupied, whitewashed, gagged, suppressed, sanitized and at best, ignored”.

4. No original: "espejo trizado".

5. No original: "reason of the Other".

6. No original: "Every word written in English represents a collaboration of sorts as well as a reorientation (conscious or unconscious) from the paradigmatic world of oral tradition to the syntagmatic reality of written language".

7. No original: "the landscape resonates the spiritual, or mythic, dimension of the Pueblo world even today"/"geographical features and landmarks that are mentioned in the narratives exist for ritual purposes".

8. No original: "visualize myself as being located within the story being told, within the landscape"/"identity was intimately linked with the surrounding terrain, to the landscape that has often played a significant role in a story or in the outcome of a conflict".

9. No original: "Land ... is the absolutely essential issue defining viable conceptions of Native America, [...] A deeply held sense of unity with particular geographical contexts has provided and continues to afford, the spiritual cement allowing cultural cohesion across the entire spectrum of indigenous American societies". 
10. No original: "sacred geography".

11. No original: "the places at which people can anchor themselves into the world, the location of things that matter" (.

12. No original: "The events of one's life take place, take place [...] I existed in that landscape, and then my existence was indivisible with it".

13. No original: "the land is our mother, the rivers our blood".

14. No original: "from us the right to prosecute non-Indians who commit crimes on our land," "the dispossession of our lands".

15. No original: "escuchan las voces de las comunidades locales, la posición de las comunidades [...] estamos queriendo el territorio para garantizar que los hijos de nuestros hijos tengan agua, conozcan siquiera un pez".

16. No original: "Y me pregunto, pues, cuando deforestamos todo ese monte ¿adónde se irán los espiritus? ¿Por qué no cuidar a esos montes sagrados?” Ver também o poema "Natureza em Chama" de Márcia Wayna Kambebe da etnia Omágoa/ Kambebe (2013, p. 57).

17. A escritora Gioconda Belli cunha este termo no seu romance $O$ país das mulheres (2011, p. 37).

18. O conceito de 'kawsay' conota existência com saúde e bem-estar baseada em experiência e prática sustentável e inclusão, justiça e igualdade social que resulta em conhecimento concreto. 'Sumak kawsay' é uma maneira de pensar e viver coletiva oposta à moderna visão do desenvolvimento baseado em indústrias extrativistas e agrobusiness. 'Kawsay' foi incorporado nas constituições do Equador (2008) e da Bolívia (2009).

19. No original: "curse of the land", "that whole edifice intricate and complex and founded upon injustice and erected by ruthless rapacity"/"wilderness", "tamed land".

20. No original: "That's what our culture is. You protect it by using it. It's the same with that place. What the people are really trying to preserve is our ways. [...] It's our ways that need to be preserved, then that place can be protected because then it has a purpose to be protected. You got to learn about them things and pass it on to others. [...] Like our language. [...] We could only preserve it by using it".

21. No original: "war and the numbers that combine to destroy life".

22. No original: "halfway between the modern world and the ancient one"/"an older world"/"wilderness".

23. Abel e Set em House Made of Dawn (1968) e The Ancient Child (1989) de N. Scott Momaday; Tayo e Indigo em Ceremony (1977) e Gardens in the Dunes (1999) de Leslie Marmon Silko; Ephanie em The Woman Who Owned the Shadows (1983) de Paula Gunn Allen; o narrador sem nome e Jim Loney em Winter in the Blood (1974) e The Death of Jim Loney (1979) de James Welch; Lulu, a filha de Fleur, em Tracks (1988) de Louise Erdrich; e Willie Begay em Ghost Singer (1988) de Anna Lee Walters, para mencionar somente alguns dos personagens da ficção indígena norte-americana que vivem crises identitárias como resultado da entre condição intra e/ou intercultural.

24. No original: "a dissolved person, like salt in water".

25. No original: "story is at the very crux of healing" / "myths [...] are the deepest, innermost cultural stories of our human journeys toward spiritual and psychological growth".

26. No original: "when people could turn into animals and animals could transform themselves into a human shape". 
27. No original: "an unbroken thread of light" / "there are unseen forces all around us".

28. No original: "her stillness"/"a full silence" / "tells you how to know things".

29. No original: "Myth is a story of a vision" / "vision is a way of becoming whole, of affirming one's special place in the universe".

30. No original: "conscious and unconscious are united through the magic of symbolic progression so that the symbols can convey direct, rational meanings and stir indirect memories and insights that have not been raised to conscious articulation".

31. No original: "in ancient dresses [...] walking slightly above the ground as if they are gliding and have no feet [...] dancing [...] drifting and singing".

32. No original: "See them walking [...]. Look at them. [...] There must be good news today. The messengers are coming".

33. Segundo Lame Deer (1972, p. 115), “quatro é o número que é mais wakan, mais sagrado. Quatro representa Tatuye Tope - os quatro cantos da terra" ("four is the number that is most wakan, most sacred. Four stands for Tatuye Tope-the four quarters of the earth").

34. No original: "and as I look it is as if I see the space between things like there's a place in between every solid thing where creation takes place".

35. Em Dwellings, Hogan observa que o objetivo de uma cerimônia é de "lembrarse que todas as coisas são ligadas" ("remember that all things are connected") e restabelecer nesse processo a relação entre os seres humanos e o universo (1995, p. 40).

36. Omishto chama o cocriador dos taiga a "nossa gata-irmã mais velha" ("our cat older sister"; p. 182). Para uma discussão da condição humana dos animais na Weltanschauung das Primeiras Nações, ver Roger Dunsmore, Earth's Mind (1997, p. 116-119).

37. No original: "song [...] prayer [...] wind"/“ life".

38. No original: "carried in something larger"/"has happened before and could happen again".

39. No original: "bring life back to this once-beautiful place".

40. No original: "I am more, at this moment, than myself. I am them. I am the old. I am the land. I am Ama and the panther. [...] All the spirits of the world congregate in air [...]. I breathe them and I feel them. In my breath is the singing of ancestors who live at the edge of sky. Like distant waves they reach a shore of the living".

41. Sobre este assunto ver, entre outros, Momaday (1975); Hogan (1983); Scharlau e Münzel (1986); Lienhard (1990).

42. No original: "ceremony and the myth. The ceremony is the ritual enactment of a specialized perception of a cosmic relationship, while the myth is a prose record of that relationship".

43. No original: "which includes ceremony, myth, tale, and song, is the primary mode of the ritual tradition".

44. No original: "to which they return continuously for theme, symbol, structure, and motivating impulse as well as for the philosophic bias that animates our work".

45. No original: "cerimonial literature"/"medicine"; "serves to redirect private emotion and integrate the energy generated by emotion within a cosmic framework".

46. No original: "is life".

47. No original: "in nearly all creation accounts [...] life was called into being through language, thought, dreaming, or singing, acts of interior consciousness". 
48. No original: "Words [...] are a person; they come from the birth throes of dream and thought. When spoken, words stand up [...] like thin gods and [...] then something newly born and alive will remain in air, in matter, in this world. That something will be here in times of need. [...] It is something that will sustain".

49. No original: "We are all the same world inside different skins, and with different intelligences".

50. No original: "the politics of the border always revolves around the tensions between imposed identity and self-definition".

51. No original: "betrayed world"

52. No original: "This building is a world cut in two. This building and what it contains divide one part of life from another. It has separated by scars, legal theft, even the stone of earth split and carried here to a building of justice, and then it covers everything broken all back over in words the way the kudzu plants from the old world cover the beautiful ground with foreign, choking vines".

53. No original: "stronger and older than America".

54. No original: "circle created by generation"/"boundary lines too thick to be drawn or made physical in this world".

55. Com relação à ligação entre genocídio, colonização e resistência na América do Norte indígena, ver Jaimes (1992).

56. No original: "the edge of the world".

57. No original: "Knowledge and truths flourish through our relationships and our connections with the natural world".

58. No original: "Self-determination means the power to define oneself and to determine one's destiny".

59. No original: "Native resistance is cultural persistence...".

\section{Referências}

ALARCÓN, Francisco. Reclaiming Ourselves, Reclaiming America. In: GONZÁLEZ, Ray (Org.). Without Discovery: A Native Response to Columbus. Seattle, WA: Broken Moon Press, 1992, p. 29-38.

ALLEN, Paula Gunn (Org.). Studies in American Indian Literature: Critical Essays and Course Designs. Nova York: Modern Language Association, 1983.

ALLEN, Paula Gunn. The Sacred Hoop. Recovering the Feminine in American Indian Traditions. Boston: Beacon Press, 1992.

AMNESTY INTERNATIONAL. Amnesty International Report 2017/18. Disponível em:https://www.amnesty.org/download/Documents/POL1067002018ENGLISH. PDF. Acesso em: 04 fev.2019.

ARMSTRONG, Jeannette. Slash. Penticton, B.C.: Theytus, 1992.

ASSINIWI, Bernard. La saga des Béothuks. Montréal: Leméac, 1996.

BASTIEN, Betty. Blackfoot Ways of Knowing: The Worldview of the Siksikaitsitapi. Calgary: University of Calgary Press, 2005.

BELLI, Gioconda. O país das mulheres. Trad. Ana Resende. Campinas: Verus, 2011.

CROW DOG, Mary (com Richard Erdoes). Lakota Woman. Nova York: Harper Perennial, 1990.

CHURCHILL, Ward. Fantasies of the Master Race: Literature, Cinema and the Colonization of American Indians Monroe, MN.: Common Courage, 1992. 
COLTELLI, Laura. Winged Words: American Indian Writers Speak. Lincoln: University of Nebraska Press, 1990.

CORNEJO-POLAR, Antonio. O Condor Voa: Literatura e Cultura Latino-Americanas. (Org. Mario J. Valdés). Belo Horizonte: EdUFMG, 2000.

DELORIA, JR., Vine. God is Red: A Native View of Religion. Golden, CO.: Fulcrum, 1994.

DUNSMORE, Roger. Earth's Mind. Albuquerque: University of New Mexico Press, 1997.

ERDRICH, Louise. The Round House. Nova York: Harper Perennial, 2012.

FASABI, Girvan T. ¿Por Qué No Cuidar a Esos Montes Sagrados? Trad. Bárbara Rodrigues. Lamas: Qinti Quartunira, 2012.

FAULKNER, William. The Bear. In: COWLEY, Malcom (Org.). The Portable Faulkner. Nova York: Penguin, 1977, p. 197-320.

GALEANO, Eduardo. Ce passé qui vit en nous. Manière de voir, 82 (août-septembre 2005), p. 91-93.

GALEANO, Eduardo. Memoria del fuego 1 - Los nacimientos. Madri: Siglo XXI, 1982.

GLISSANT, Édouard. Caribbean Discourse. Charlottesville: University Press of Virginia,1992.

GRAÚNA, Graça. Canción peregrina. In: NEARIN; INBRAP; SEC. Antologia indígena. Mato Grosso: SEC, 2009, p. 27-28.

GRAÚNA, Graça. Manifesto I. Disponível em: overmundo.com.br/banco/manifesto-i, 20/02/2010. Acesso em: 07 nov. 2019.

GRAÚNA, Graça. O Guarani. Canto mestizo. Maricá, RJ: Blocos, 1999, p. 51.

GRAÚNA, Graça. Poética da autonomia. Disponível em: www.recantodasletras.com. br/poesias-do-social/2532550. Acesso em: 12 dez. 2018.

GRAÚNA, Graça. Resistência. Cadernos Negros 29. São Paulo: Quilombhoje, 2006, p. 120.

GROSSBERG, Lawrence. We Gotta Get Out of This Place: Popular Conservatism and Postmodern Culture. Nova York: Routledge, 1992.

HOGAN, Linda. Dwellings: A Spiritual History of the Living World. Nova York: W.W. Norton \& Company, 1995.

HOGAN, Linda. Introduction. Intimate Nature: The Bond between Women and Animals. In: HOGAN, Linda; METZGER, Deena; PETERSON, Brenda (Orgs.). Nova York: The Ballantine Publishing Group, 1998a.

HOGAN, Linda. Power. Nova York: Norton, 1998b.

HOGAN, Linda. Who Puts Together. In: ALLEN, Paula G. (Org.). Studies in American Indian Literature: Critical Essays and Course Designs. Nova York: Modern Language Association, 1983, p. 169-177.

JAIMES, M. Annette (Org.). The State of Native America: Genocide, Colonization, and Resistance. Boston: South End Press, 1992.

JECUPÉ, Kaka Werá. A terra dos mil povos: história indígena brasileira contada por um índio. Ed. Fundação Petrópolis, 1998.

KAMBEBE, Márcia Wayna. Natureza em Chama. Ay Kakyri Tana (Eu Moro na Cidade). Ed. Manaus Gráfica, 2013.

KRASTEVA, Yonka Kroumova. The Politics of the Border in Linda Hogan's Mean Spirit. Studies in American Indian Literatures, University of Nebraska, Lincoln, v. 11, n. 4, p. 46-60, Inverno, 1999. 
LAME DEER, John (Fire); ERDOES, Richard. Lame Deer, Seeker of Visions. Nova York: Touchstone, 1972.

LIENHARD, Martin. La voz y su huella. La Habana: Casa de las Américas, 1990.

MARIÁTEGUI, José Carlos. 7 ensayos de interpretación de la realidad peruana. Buenos Aires: Capital Intelectual, 2009.

MOMADAY, N. Scott. The Man Made of Words. CHAPMAN, Abraham (org.) Literatures of the American Indians: Views and Interpretations. Nova York: Meridian, 1975, p. 96-110.

MOMADAY, N. Scott. The Names. A Memoir. Nova York: Harper and Row, 1976.

ORGANIZATION OF AMERICAN STATES. OAS American Declaration on the Rights of Indigenous Peoples. Disponível em: https://www.iitc.org/programareas/treaties-standard-setting/the-oas-american-declaration-on-the-rights-ofindigenous-peoples/Acesso em: 04 mar. 2019.

ORGANIZATION OF AMERICAN STATES. Declaration of OAS Human Rights. $46^{\text {th }}$ Session of the General Assembly. Disponível em: https://www.oas.org/en/sare/ documents/DecAmIND.pdf. Acesso em: 15 jan. 2020.

OWENS, Louis. Other Destinies: Understanding the American Indian Novel. Norman: University of Oklahoma Press, 1992.

POWER, Susan. The Grass Dancer. Nova York: Picador, 1995.

QUIJANO, Anibal.La colonialidad del poder yla experiencia culturallatinoamericana. In: BRICEÑO-LEÓN, Roberto; SONNTAG, Heinz R. (Orgs.). Pueblo, época y desarrollo: la sociología de América Latina. Caracas: Nueva Sociedad 1998, p. 139-155.

RICH, Adrienne. When We Dead Awaken: Writing as Re-Vision. On Lies, Secrets, and Silence: Selected Prose 1966-1978. Nova York: W.W. Norton and Company, 1979, p. 33-49.

SCHARLAU, Birgit; MÜNZEK, Mark. Qellqay. Mündliche Kultur und Schrifttradition bei Indianern Lateinamerikas. Frankfurt: Campus, 1986.

SCHWARZ, Roberto. Nacional por Subtração. Que horas são? São Paulo, Companhia das Letras, 1989.

SILKO, Leslie M. Yellow Woman and the Beauty of the Spirit. Essays on Native American Life Today. Nova York: Touchstone, 1997.

SOJA, Edward. Postmodern Geographies: The Reassertion of Space in Critical Social Theory. London: Verso, 1989.

UNITED NATIONS. United Nations Declaration on the Rights of Indigenous Peoples. Disponível em: https://www.un.org/development/desa/indigenouspeoples/wpcontent/uploads/sites/19/2018/11/UNDRIP_E_web.pdf. Acesso em: 24 abr. 2019.

VALASKAKIS, Guthrie G. Indian Country: Essays on Contemporary Native Culture. Waterloo, Ont.: Wilfried Laurier UP, 2005.

WALCOTT, Derek. The Muse of History. In: ASHCRAFT, Bill; GRIFFITHS, Gareth; TIFFIN, Helen (Orgs.). The Post-Colonial Studies Reader. Nova York: Routledge, 1995.

Recebido em: 11/05/2020

Aceito em: 22/07/2020 